Petra Testen, ${ }^{*}$ Tadej Koren ${ }^{* *}$

\title{
Učilnica na prostem - Primer Poti miru
}

\section{IZVLEČEK}

Pot miru od Alp do Jadrana je projekt, ki je nastal pod okriljem Ustanove "Fundacija Poti miru v Posočju«. V naravi gre za traso, ki poteka po ostalinah soške fronte, idejno pa izpostavlja vrednoto miru in spomina nujnega dela kolektivne zavesti naroda, ki tudi tragedijo prve vojne lahko sporoča v luči pomembne dediščine preteklosti. Kot taka je izjemen didaktični element, saj avtentične lokacije, prostori spomina, ponujajo neposredno vez s preteklim in omogočajo učinkovito izvajanje učilnice na prostem.

Ključne besede: prva svetovna vojna, učilnica na prostem, prostor spomina, Pot miru od Alp do Jadrana

ABSTRACT

\section{OPENAIR CLASSROOM: THE WALK OF PEACE EXAMPLE}

The Walk of Peace from the Alps to the Adriatic is a project created under the auspices of the Walk of Peace in the Soća Region Foundation. The Walk of Peace is a trail following the remnants of the Isonzo Front. Its intention is to emphasise the values of peace and remembrance of an essential part of the nation's collective consciousness, conveying the tragedy of World War I in light of the important historical heritage. Thus this trail is an extraordinary didactic element, as its authentic locations and areas of remembrance provide a direct link with the past and allow for the efficient implementation of an openair classroom.

Keywords: World War I, openair classroom, area of remembrance, the Walk of Peace from the Alps to the Adriatic

"Pot miru je prostor spomina, je pot pohoda skozi zgodovino, spoznavanja prostorov, mikro-svetov vojnega vsakdana pod pekočim poletnim soncem, pod zakloni skalnega previsa, $v$ strelskih jarkih Doberdobske planote, mimo obeležij, ki so zaznamovala položaje

* dr., znanstvena sodelavka, Inštitut za kulturno zgodovino ZRC SAZU, Novi trg 2, p.p. 306, SI-1001 Ljubljana (Filozofska fakulteta, Univerza v Ljubljani, Inštitut za civilizacijo in kulturo), ptesten@gmail.com

** mag., Ustanova »Fundacija Poti miru v Posočju«, Gregorčičeva 8, SI-5222 Kobarid, fundacija. potimiru@siol.net 
vojaških enot in nazadnje vzdolž spominske poti pripeljala v spokojnost poslednjih počivališč.

Trg Evrope, v italijanski različici Piazza della Transalpina, je skupni trg obeh Goric - Nove Gorice in Gorice ${ }^{2}$ ob slovensko-italijanski meji, ki naj bi predstavljal simbolno mesto povezovanja med Slovenijo in Italijo. Gre za območje okrog avstro-ogrske železniške postaje, ki so jo odprli leta 1906; trg je urejal že Max Fabiani, na osnovi njegove zapuščine pa ga je dokončno rešil Romano Schnabl. ${ }^{3}$ Od vstopa Slovenije v Evropsko unijo 1. maja 2004 trg krasi mozaik nove Evrope, ki ga je zasnoval tržaški umetnik Franko Vecchiet. ${ }^{4} \mathrm{Na}$ trgu, ki leži vzdolž nekdanje soške fronte, poteka danes trasa Poti miru od Alp do Jadrana, "otrok« Ustanove "Fundacija Poti miru v Posočju« s svojim sedežem v Kobaridu. Trg Evrope danes spominja in opominja na dogodke izpred stotih let, obenem pa ponuja alternativo - kulturo povezovanja onkraj meja in ideologij, kjer se v miru stikata preteklost in prihodnost. Kaj je torej Pot miru od Alp do Jadrana in zakaj bi bil ta projekt primeren kot učilnica na prostem, ki jo napoveduje že naslov pričujočega prispevka? Kaj ga dela posebnega, zanimivega? Kateri elementi tega projekta vsebujejo didaktični potencial? Od kod ideja in kaj

1 Prof. dr. Petra Svoljšak je predstojnica Zgodovinskega inštituta Milka Kosa, ZRC SAZU, obenem pa podpredsednica Nacionalnega odbora za obeleževanje 100-letnice 1. svetovne vojne (2014-2018). Petra Svoljšak, "Vodniku na pot (iz uvodne besede), « v: Tadej Koren, Pot miru od Alp do Jadrana. Vodnik po soški fronti (Kobarid: Ustanova Fundacija Poti miru v Posočju, 2015), 9. (Vodnik je na razpolago tudi v italijanskem in angleškem jeziku: Tadej Koren, Il Sentiero della pace dalle Alpi all'Adriatico. Guida lungo il fronte isontino, prev. Michele Obit (Kobarid: Ustanova Fundacija Poti miru v Posočju, 2015). Tadej Koren, The Walk of Peace from the Alps to the Adriatic. A guide along the Isonzo Front, prev. Branka Klemenc (Kobarid: Ustanova Fundacija Poti miru v Posočju, 2015).

2 Mesto Gorica (Italija) je imelo med prvo svetovno vojno status simbola, saj je kot strateška točka, največji kraj med Alpami in Trstom, odpiralo vrata v notranjost avstrijskih dežel.

3 Železniške povezave so bile v "starem svetu" pomembno okno v svet, obenem pa dejavnik tako urbanega kot gospodarskega razvoja mesta, ki so ga dosegle. Trst je bil z zadnjim delom trase južne železnice povezan z Ljubljano in dalje z Dunajem leta 1857, medtem ko je Gorico dosegla prva železniška povezava $\mathrm{v}$ letu 1860. Dokončna železniško-prometna mreža na tem področju je bila zgrajena leta 1906, ko je bohinjska železnica povezala Gorico s Koroško (Beljak) na severu in Trstom na jugu. Znotraj dežele sta bila pred tem zgrajena še dva tira, in sicer t. i. furlanska železnica, ki je povezovala Tržič in Červinjan (1894), ter trasa med Gorico in Ajdovščino (1902). Glej npr.: Branko Marušič, Pregled politične zgodovine Slovencev na Gorǐ̌kem:1848-1899 (Nova Gorica: Goriški muzej, 2005), 62.

4 Koren, Pot miru od Alp do Jadrana, 97. Pričujoče besedilo temelji na podlagi že obstoječih študij, in sicer: Tadej Koren, "Zgodovinski spomin na soško fronto - Pot miru od Rombona do Mengor" (magistrsko delo, Filozofska fakulteta Univerze v Ljubljani, 2012). Tadej Koren in Petra Testen, „Spomin, prostor in ostaline soške fronte: primer Poti miru, " v: Velika vojna in mali ljudje, ur. Igor Grdina (Šentjur: Knjižnica; Ljubljana: Inštitut za civilizacijo in kulturo - ICK, 2014), 67-78. Tadej Koren in Petra Testen, "Vospominanie o Pervoj mirovoj vojne. Rol' prostranstva i nasledija Sočanskogo fronta dlja zitelej Posočja, « v: Slovenica. 3, Pervaja mirovaja vojna v politike i kul'ture Russkih i Slovencev: $k$ stoletiju načala pervoj mirovoj vojny, ur. Konstantin V. Nikiforov (Moskva: Institut slavjanovedenija Rossijskoj akademii nauk, 2014), 252-75. Tadej Koren, "Das Erbe der Isonzofront nach 100 Jahren - Weg des Friedens, "v: Krieg und Tourismus im Spannungsfeld des Ersten Weltkrieges / Guerra e turismo nell'area di tensione della prima guerra mondiale, ur. Patrick Gasser et al. (Innsbruck, Wien, Bozen: Studien Verlag, 2014), 445-66. 


\section{Slika 1: Avstro-ogrsko vojaško pokopalǐše, Log pod Mangartom, Slovenija}

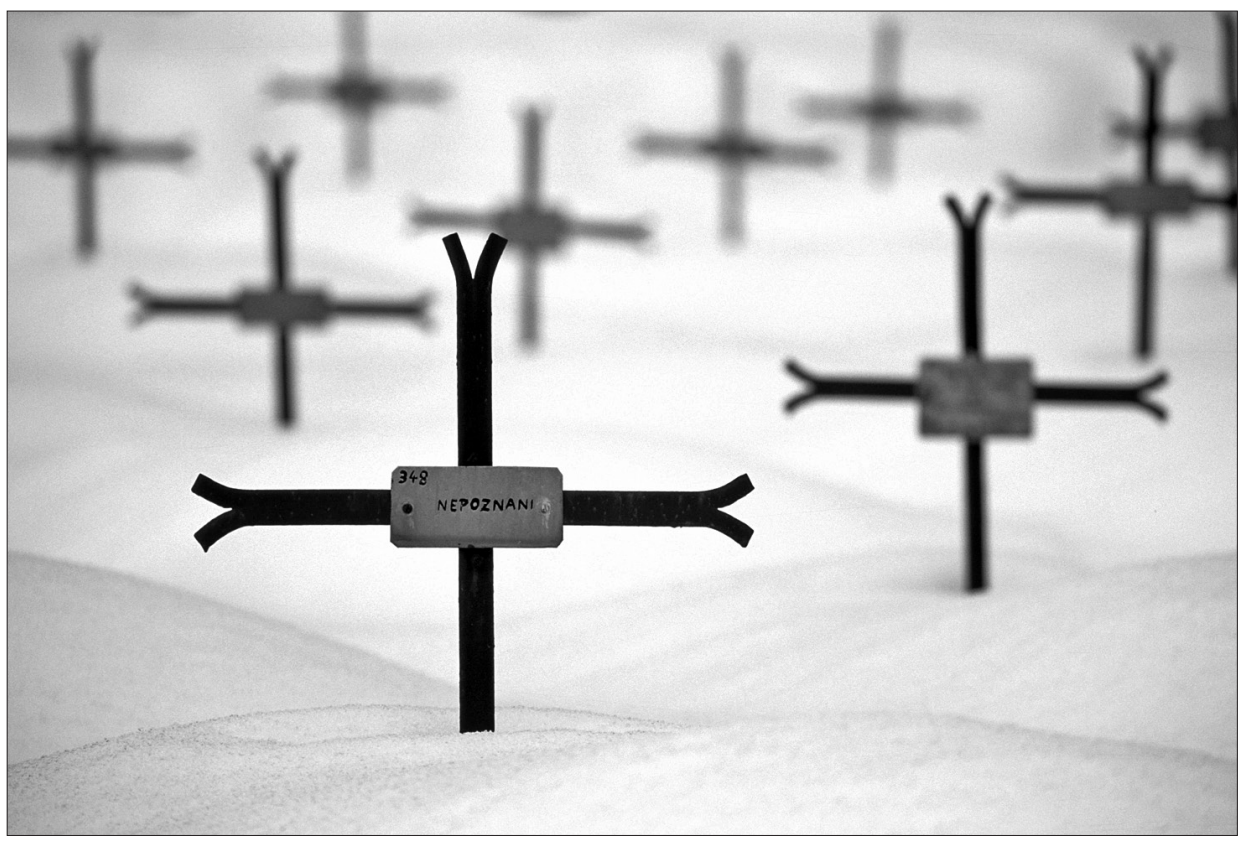

Vir: Ustanova "Fundacija Poti miru v Posočju»

nam sporoča? Zakaj poimenovanje Pot miru? Kaj je prostor spomina? Odgovori na ta vprašanja sestavljajo zgodbo, v kateri se prepletajo naracije obsoškega prostora, življenja prebivalcev doline ob smaragdni reki in vloga spomin(janj)a ter njenega vrednotenja. Gre za lok med preteklostjo, sedanjostjo in prihodnostjo.

Zgodovinsko dogajanje pred stotimi leti je soško dolino in obsoško prebivalstvo zagotovo močno zaznamovalo. Poleg spominov, memoarjev, pričevanj, ki so se predajala iz roda v rod, se je vse do danes ohranilo tudi veliko ostalin (kaverne, strelski jarki, kapele, spominska obeležja, vojaška pokopališča), te pa predstavljajo zelo pomembno zgodovinsko dediščino. Ustanova »Fundacija Poti miru v Posočju« je bila osnovana z namenom, da to dediščino prve svetovne vojne ohranja, obenem pa jo posreduje čim širšemu krogu ljudi. Podobne prakse srečamo tudi drugod po zahodni Evropi, le da se je tam spominu na prvo vojno že kmalu po krvavih dogodkih posvečalo več časa in prostora in je poklon padlim hitreje postal del tradicije, zapisa v kolektivni spomin narodov, ki se je obenem nerazdružljivo spojil z vrednoto miru. Sama ideja za vzpostavitev Poti miru v Zgornjem Posočju in iniciativa po razširitvi te poti na celotno območje nekdanje soške fronte sta rasli ob zgledih »dobrih praks« na podobnih zgodovinskih območjih v zahodnoevropskih državah. ${ }^{5}$ Predvsem urejena

5 Glej npr.: Dolomitenfreunde, pridobljeno 28. 9. 2015, http://www.dolomitenfreunde.at. Associazione Storica Cimeetrincee, pridobljeno 28. 9. 2015, http://www.cimeetrincee.it. CarniaMusei, pridobljeno 28. 9. 2015, http://www.carniamusei.org. I LUOGHI DELLA GRANDE GUERRA NEL 


\section{Slika 2: Zasebna muzejska zbirka Botognica, Drežnica, Slovenija}

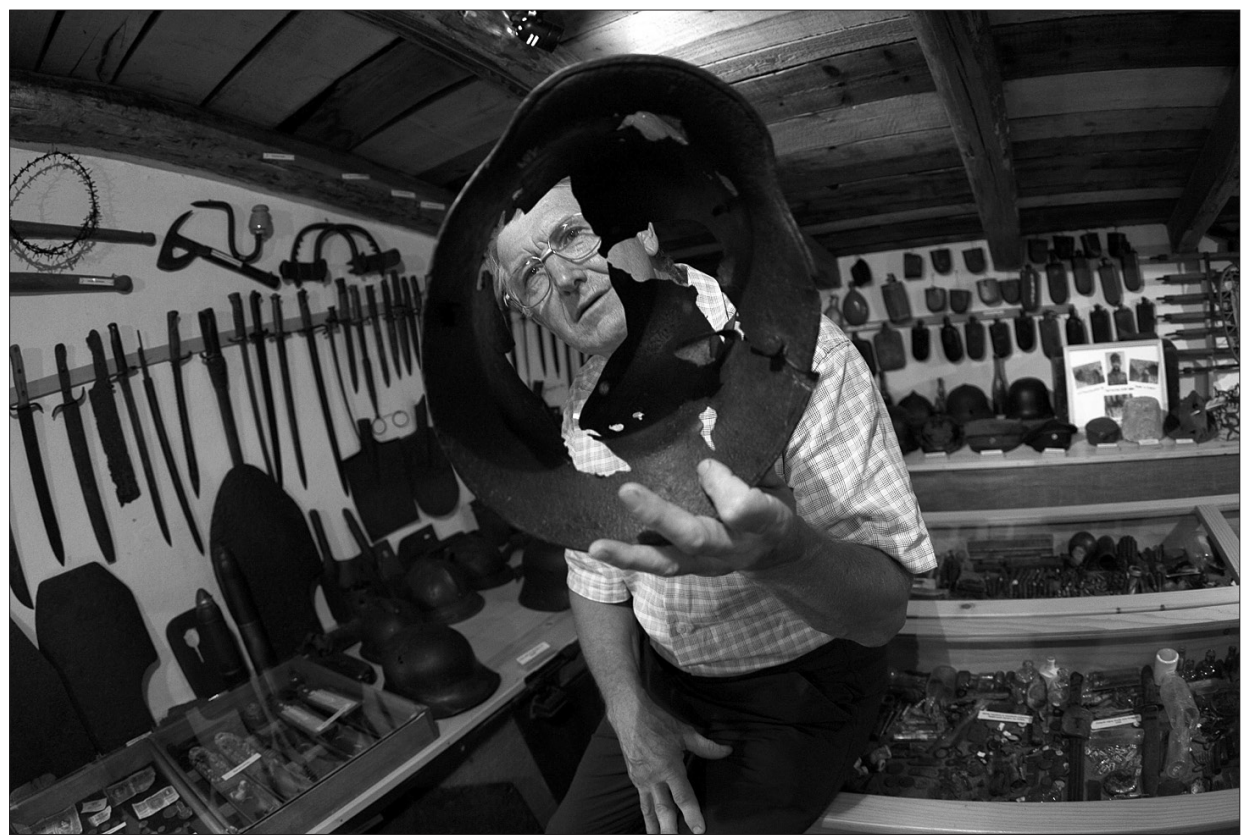

Vir: Ustanova "Fundacija Poti miru v Posočju«

spominska območja v Dolomitih in Karnijskih Alpah, kjer so začeli urejati Poti miru že v osemdesetih in devetdesetih letih prejšnjega stoletja, so bila v veliko oporo pri idejnem načrtovanju projekta v Posočju. Podobno velja tudi za Francijo z Verdunom in Somo, saj območji dobesedno živita od zgodovinskega turizma. Skupna lastnost vseh teh urejenih zgodovinskih prostorov je, da ležijo na avtentičnih lokacijah nek-

FRIULI COLLINARE. RAGOGNA, FORGARIA NEL FRIULI E SAN DANIELE DEL FRIULI, pridobljeno 28. 9. 2015, http://www.grandeguerra-ragogna.it. MUSEO STORICO ITALIANO DELLA GUERRA, pridobljeno 28. 9. 2015, http://www.museodellaguerra.it. Grandeguerra.Dolomiti.Org, pridobljeno 28. 9. 2015, http://www.grandeguerra.dolomiti.org. STELVIO-UMBRAIL 14/18. Mit uns in die Geschichte wandern, pridobljeno 28. 9. 2015, http://www.stelvio-umbrail.ch. "Battles - The Battle of the Somme, 1916, « firstworldwar.com. a multimedia history of world war one, pridobljeno 28. 9. 2015, http://www.firstworldwar.com/battles/somme.htm. "Battles - The Battle of Verdun, 1916," firstworldwar.com. a multimedia history of world war one, pridobljeno 28. 9. 2015, http://www.firstworldwar.com/battles/verdun.htm. „CIRCUIT DU SOUVENIR, « Musée de la Première Guerre mondiale / 1914-1918. HISTORIAL DE LA GRANDE GUERRE, pridobljeno 28. 9. 2015, http://www. historial.org/Champs-de-bataille-de-la-Somme/Circuit-du-souvenir. MÉMORIAL DE VERDUN. Réouverture en février 2016, pridobljeno 28. 9. 2015, http://www.memorial-de-verdun.fr. Musée de la Première Guerre mondiale / 1914-1918. HISTORIAL DE LA GRANDE GUERRE. Péronne - Thiepval / Somme, pridobljeno 28. 9. 2015, http://www.historial.org. "Thiepval Memorial to the Missing, Somme Battlefields, France, «THE GREAT WAR 1914-1918, pridobljeno 28. 9. 2015, http://www. greatwar.co.uk/somme/memorial-thiepval.htm. IN FLANDERS FIELDS MUSEUM, pridobljeno 28. 9. 2015, http://www.inflandersfields.be/en/discover. Toerisme Ieper, pridobljeno 28. 9. 2015, http:// www.toerisme-ieper.be itd. Več glej: Koren, "Zgodovinski spomin na soško fronto«, 86-107. 
danjih frontnih črt. Glavni namen in vrednost pa je prav v njihovi sporočilnosti, ki poudarja vrednoto miru in vzpostavitev mednarodnega (spo)razumevanja. ${ }^{6} \mathrm{Na}$ tej idejni osnovi, vključno z imenom, je zrasla tudi Pot miru vzdolž nekdanje soške fronte. Danes je posoški projekt primer »dobre prakse« za številne države, ki se nahajajo ob nekdanji vzhodni fronti in vzpostavljajo lastne urejene prostore spomina.

Posočje je vsekakor edinstveno okolje, kjer lahko spremljamo preplet zgodovinske dediščine in naravnih lepot. Tu živijo ljudje, ki (so)ustvarjajo krajino, ko na primer pišejo gastronomske zgodbe, živijo svoja življenja, a se hkrati spominjajo in sobivajo z vso (nepremično) dediščino prve svetovne vojne. Tudi in predvsem zato je Posočje odličen primer, kako se (kolektivni) spomin navezuje na prostor. Gre namreč za skupino ljudi, ki je ujeta $v$ določen prostorski okvir, tega pa še dodatno zapira moč materialnega okolja, ki skupino obdaja. Prav prostorski okvir je za Posočje in dojemanje odnosa do (materialne) dediščine soške fronte eden najpomembnejših dejavnikov. ${ }^{7}$ Zaznamovanost $s$ prostorom in vsemi materialnimi ostalinami je torej ključno pripomogla k temu, da je (kolektivni) spomin na soško fronto med domačini v Posočju ostal tako živ. Prav tu so se na primer nekateri posamezniki samoiniciativno odločili ohranjati dediščino tudi tako, da so v povojnih letih ustvarjali zasebne zbirke, ki so danes vključene v projekt Pot miru. ${ }^{8}$ Ne nazadnje je skrb za spominski kraj oziroma prostor zagotovo eden izmed načinov ohranjanja živosti kolektivnega spomina. V študiji z naslovom Der Isonzoraum - Eintransnationaler Gedächtnisort für Österreicher, Italiener und Slowenen Andrea Brait analizira in utemeljuje pomen spominskega kraja prav na primeru prostora ob Soči - razume in vidi ga kot transnacionalni spominski kraj za Avstrijce, Italijane in Slovence. ${ }^{9}$ Prostor torej lahko spodbuja, da se spominjamo. Na podoben način pa lahko postane spominsko območje vseh, ki so kakor koli povezani z njim. Zagotovo ima Posočje velik pomen za domačine, ki se $\mathrm{z}$ materialno dediščino vojne vsakodnevno srečujejo, se zavedajo tudi njenega

6 Koren, "Zgodovinski spomin na soško fronto«, 86.

7 Koren, Testen, »Spomin, prostor in ostaline soške fronte«, 72-73.

8 Zasebne zbirke, ki so vključene v Pot miru od Alp do Jadrana: Mali muzej soške fronte Bovec, Miloš Domevšek (Bovec). Muzejska zbirka Iva Ivančiča, Ivan Ivančič (Bovec). Vojaška zbirka Zbogom orožje 1915-1917, Sašo Prochazka (Bovec). Muzejska zbirka Stol 1915-1917, Zdravko Marcola (Breginj). Etno-vojna zbirka, Valentin Mazora (Breginj). Zbirka Botognice, Mirko Kurinčič (Drežnica). Muzejska zbirka Posočje 1915-1917, Matic Volarič (Idrsko). Zbirka prve svetovne vojne Alberto Picco, Bojan Rustja (Kobarid). Kobarid v véliki vojni 1917, Ivo Krajnik (Kobarid). Mali muzej soške fronte Tolminsko mostišče, Peter Kogoj (Most na Soči). Muzejska zbirka Franca Jerončiča, Franc Jerončič (Kanal). Jugova zbirka, Martin Levpušček (Kanal). Lukčeva hiša, Jožica Strgar (Kambreško). Muzejska zbirka 1914-1917, Zoran Šuligoj (Kanal). Muzejska zbirka na Sabotinu, Bogdan Potokar. Vojni muzej Solkan, Rok in Jordan Boltar (Solkan). Stalna razstava Društva soška fronta Šempeter in okolica med prvo svetovno vojno, David Erik Pipan (Šempeter). Zgodovinski muzej Balus, Matteo Balus (Srednje / Stregna). Več o zasebnih zbirkah glej: »Kulturna dediščina v zbirkah med Alpami in Krasom. / Leredità culturale nelle collezioni fra Alpi e Carso, «Zborzbirk, pridobljeno 28. 9. 2015, http://zborzbirk.zrc-sazu.si.

9 Andrea Brait, "Der Isonzoraum - Ein transnationaler Gedächtnisort für Österreicher, Italiener und Slowenen, "v: Waffentreue. Die 12. Isonzoschlacht 1917, Begleitband zur Ausstellung des Österreichischen Staatsarchiv, 23. Oktober 2007-1. Februar 2008, ur. Manfried Rauchensteiner (Wien: Österreichischen Staatsarchiv, 2007), 115-30. 
ekonomskega potenciala, še bolj pa dejstva, da se je na njihovem pragu odigralo pomembno poglavje svetovne zgodovine. Nič manj pa ni to spominsko območje pomembno za številne druge, na primer za potomce vojakov, ki so se v teh krajih borili med prvo svetovno vojno, ${ }^{10}$ šoloobvezne otroke, ki spoznavajo to obdobje zgodovine itd. Na ta način prostor ob Soči postaja zgodovinski kraj, trdi Braitova, in kot tak zgodovinski termin. In prav zato, ker je Posočje posejano s spominskimi kraji, je toliko bolj razumljivo, da se je prav tu spomin na soško fronto tako močno ohranil. $S$ tem je namreč skladna tudi Halbwachsova teza, da "[n]i kolektivnega spomina, ki se ne bi dogajal v prostorskem okviru «. ${ }^{11} \mathrm{Od}$ tu pa do didaktičnega pripomočka, ki $\mathrm{v}$ živo, nazorno prikliče tudi in predvsem $s$ pomočjo krajine naracijo o prvi vojni in tako ponuja neposredni okvir pouku o spominu, je le korak.

Naj ponazorimo še z enim primerom, kako močno deluje prostor na obiskovalce. Gre za t. i. romanja na zgodovinske kraje, množična obiskovanja nekdanjih bojišč, ki so pravzaprav na prostor spominjanja vezana družinska romanja, na katera opozarjata Jay Winter in Emmanuel Sivan, ko govorita o generacijah, ki so doživele prvo vojno in so se po njej vračale na prizorišča nekdanjih bojev (battlefieldstours). ${ }^{12}$ Danes enako počno njihovi potomci. Razlago za "romanja" gre najverjetneje iskati v dejstvu, da je prav avtentična lokacija tista, ki obiskovalce evocira, jih nagovarja, jim pomaga podoživeti dogodke in obuditi spomine na pripovedi preminulih sorodnikov. In prav avtentične lokacije v Posočju so temelj, na katerem gradi svoje delo tudi Ustanova »Fundacija Poti miru v Posočju «; na teh zgodovinskih krajih prve svetovne vojne so pred leti uredili najprej šest muzejev na prostem v Zgornjem Posočju, danes pa skrbijo za materialne ostaline vzdolž nekdanje frontne črte, združene v Pot miru od Alp do Jadrana. Poleg tega je Fundacija v sodelovanju s Tolminskim muzejem uredila evidenco padlih vojakov, saj so se svojci padlih vse pogosteje zanimali za kraje poslednjega počitka svojih prednikov. Ta podatkovni nabor, ki je narejen za območje Zgornjega Posočja in šteje približno 21.000 padlih vojakov, privablja - če si izposodimo terminologijo Winterja in Sivana - še več »romarjev«. ${ }^{13}$

Prav zaradi močnega (samo)zavedanja o moči spomin(janj)a na avtentičnih lokacijah, sredi ostalin prve svetovne vojne, ni torej nič nenavadnega, da se je v tem okolju porodila ideja za delovanje ustanov, kot sta Kobariški muzej ${ }^{14}$ in Ustanova

10 Vedno več obiskovalcev nekdanjega obsoškega bojišča (Madžari, Čehi, Slovaki, Bošnjaki) prihaja v te kraje tudi z željo, da bi videli, kje so se borili njihovi predniki. Veliko svojcev išče grobove padlih vojakov, sorodnikov, saj mnogi med njimi še vedno počivajo v Posočju.

11 Maurice Halbwachs. Kolektivni spomin (Ljubljana: Studia humanitatis, 2001), 157.

12 Jay Winter in Emmanuel Sivan, "Setting the framework, "v: War and Remembrance in the Twentieth Century, ur. Jay Winter in Emmanuel Sivan (Cambridge, New York, Melbourne, Madrid, Cape Town, Singapore, São Paulo: Cambridge University Press, 2005), 37.

13 Evidenca padlih vojakov v Zgornjem Posočju je dostopna na svetovnem spletu ("Evidenca padlih, « POT MIRU, pridobljeno 28. 9. 2015, http://www.potmiru.si/slo/evidenca-padlih) in objavljena v knjigah: Lovro Galić in Branko Marušič, Tolminsko mostišče I (Tolmin: Tolminski muzej, 2005). Petra Svoljšak et al., Tolminsko mostišč II (Tolmin: Tolminski muzej, 2005). Lovro Galić in Darja Pirih, Od Krna do Rombona (Kobarid: Ustanova Fundacija Poti miru v Posočju, Tolminski muzej, 2007).

14 Glej: KOBARIŠKI MUZEJ, pridobljeno 28. 9. 2015, http://www.kobariski-muzej.si. Poleg 


\section{Slika 3: Muzej na prostem Čelo, Bovec, Slovenija}

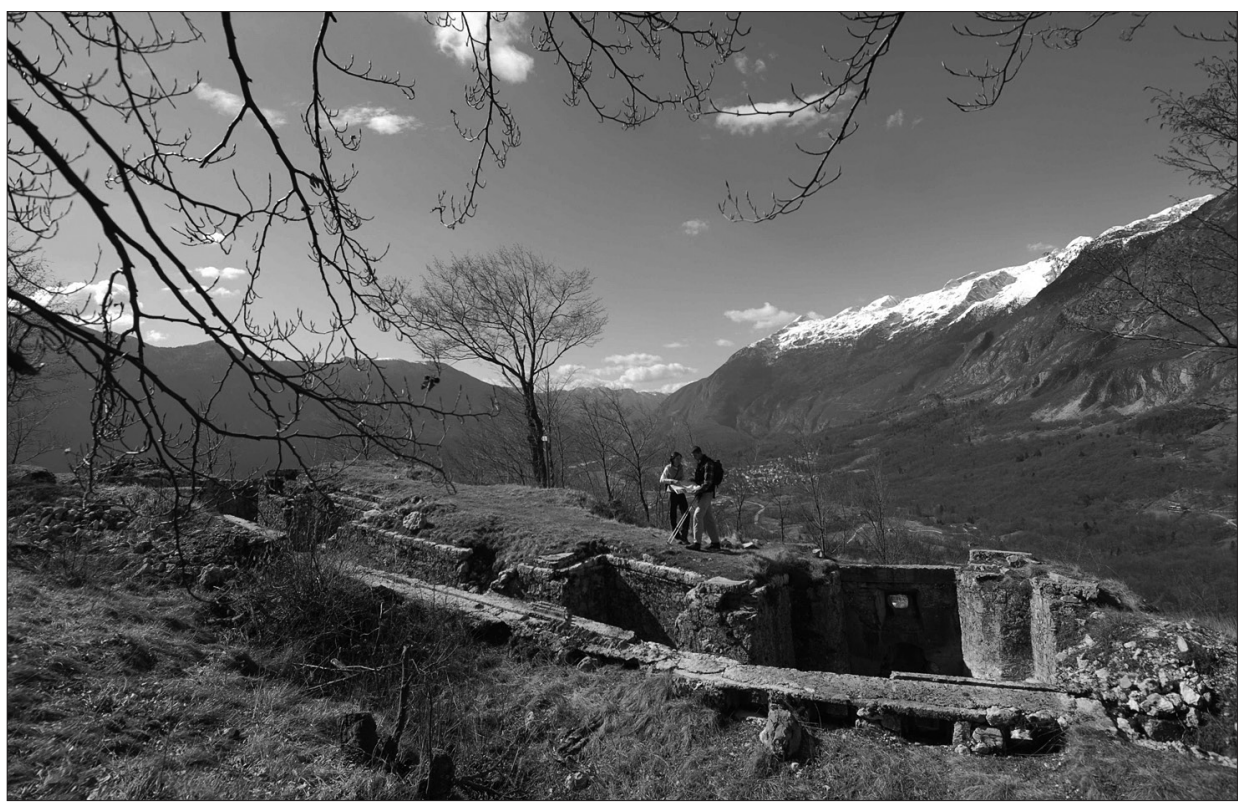

Vir: Ustanova "Fundacija Poti miru v Posočju«

»Fundacija Poti miru v Posočju «. Prvi se je razvil iz muzejske zbirke, ki so jo leta 1990 uredili domačini. Najprej je deloval v okviru Turističnega društva Kobarid, v soglasju z Ministrstvom za kulturo Republike Slovenije pa so ustanovitelji po petih letih prenesli upravljanje na zasebno neprofitno družbo z omejeno odgovornostjo, ki z muzejem upravlja še danes. Muzej je leta 1993 za predstavitev svoje zbirke prejel nagrado Sveta Evrope za najboljši muzej. Naslednji korak je bil dokaj logičen - poskrbeti je bilo treba še za materialno dediščino prve svetovne vojne v naravi. V krogu sodelavcev Kobariškega muzeja je bila dana pobuda za osnovanje Ustanove »Fundacija Poti miru v Posočju«. Nato je Vlada Republike Slovenije leta 2000 ustanovila Fundacijo z namenom, da bi ohranjala in vzdrževala nepremično dediščino soške fronte. V preteklih letih so se pod njenim okriljem tako začele izvajati številne dejavnosti, glavna pa

Kobariškega muzeja danes ob Poti miru od Alp do Jadrana najdemo v Sloveniji še Tolminski muzej (Tolminski muzej, pridobljeno 28. 9. 2015, http://www.tol-muzej.si.) in Goriški muzej (Goriški muzej, pridobljeno 28. 9. 2015 (stran trenutno v popravilu), http://www.goriskimuzej.si.), na italijanski strani pa Museo della Grande Guerra di Gorizia (musei@provincia.gorizia.it), Museo della Grande Guerra del Monte San Michele, Museo della Grande Guerra Casa III Armata, Devinski grad / Castello di Duino (Castello di Duino, pridobljeno 28. 9. 2015, http://www.castellodiduino.it.), Civico Museo della Guerra per la Pace Diego de Henriquez (H. MUSEO DELLA GUERRA PER LA PACE DIEGO DE HENRIQUEZ, pridobljeno 28. 9. 2015, http://www.museodiegodehenriquez.it.), Museo del Risorgimento (museorisorgimento@comune.trieste.it), Sala storica della Sezione G. Corsi di Trieste Associazione Nazionale Alpini di Trieste (trieste@ana.it), Museo dell'Associazione Culturale F. Zenobi (info@ zenobionline.com), Museo privato Ricordi della Grande Guerra in Stazione Multimediale, Museo della Grande Guerra. Več glej: Koren, Pot miru od Alp do Jadrana, 203. 
je prav gotovo projekt Pot miru, ki zajema predvsem skrb za nepremično dediščino soške fronte in njeno poznavanje med čim širšim krogom ljudi.

Kako se je torej dejansko uresničeval projekt Poti miru? Sprva je bila načrtovana in urejena trasa v Zgornjem Posočju. Leta 2007 je tako nastala sto kilometrov dolga pešpot, ki je povezovala ostaline soške fronte $\mathrm{v}$ naravi, posvečena pa je bila predvsem spominu na številne žrtve prve svetovne vojne. Pot je bila speljana tako, da danes vodi mimo vojaških pokopališčc, kostnic, sakralnih objektov, spominskih obeležij, jarkov, utrdb, kavern in muzejev na prostem ter zasebnih zbirk, obiskovalce pa popelje tudi mimo naravnih in kulturnih znamenitosti ter etnografskih posebnosti Zgornjega Posočja. Prične se v Logu pod Mangartom, v bližini vojaškega pokopališča, kjer je vhod v rudniški jašek Štoln (iz nem. der Stollen), poteka mimo trdnjave Kluže, Cerkve Sv. Duha v Javorci, ${ }^{15}$ številnih še živih planin, naravnih znamenitosti, kot so tolminska korita, in še in še. Stokilometrska Pot miru v Zgornjem Posočju je razdeljena na pet odsekov, ki vsak zase poudarjajo posebnosti posameznega območja in potekajo od Bovškega preko Kobariškega do Tolminskega področja. Pri tem zagotovo zaslužijo posebno pozornost muzeji na prostem, ki so vsak zase kot priročne učilnice na prostem. ${ }^{16} \mathrm{~V}$ zgornjem Posočju jih je šest, in sicer: Ravelnik (avsto-ogrska prva obrambna črta, Bovec), Čelo (avstro-ogrski topniški položaji, Bovec), Zaprikraj (prva italijanska obrambna črta, Kobarid), Kolovrat (tretja italijanska obrambna črta, Kobarid), Mrzli vrh (avstro-ogrska in italijanska prva obrambna črta, Tolmin) in Mengore (avstro-ogrska prva obrambna črta, Tolmin). Gre za šest večjih področij, kjer so bile vojne ostaline »bolj na gosto posejane« in dobro ohranjene, zato jih je Fundacija skupaj z zgodovinskimi in turističnimi društvi ${ }^{17}$ iz Zgornjega Posočja ter Zavodom za varstvo kulturne dediščine $(\mathrm{ZVKD})^{18}$ uredila, očistila in označila.

15 Javorca, spominska cerkev Svetega Duha je posvečena padlim avstro-ogrskim vojakom, ki so branili tolminsko bojišče (1915-1917), in je eden izmed lepših spomenikov prve svetovne vojne; leta 2007 je bil uvrščen med tiste, ki nosijo znak evropske kulturne dediščine. Objekt je zasnoval Remigius Geyling (1878-1974), gradnjo pa izpeljal poročnik Géza Jablonszky. Spodnji del tega secesijskega dragulja in obzidje je iz kamna, medtem ko je preostali del konstrukcije iz macesna. V notranjosti je na hrastovih ploščah, ki simbolizirajo liste spominske knjige, vžganih 2565 imen padlih vojakov, danes pokopanih v Ločah pri Tolminu. Glej npr: POT MIRU, pridobljeno 28. 9. 2015, http://www.potmiru.si.

16 Tadej Koren, "Pot po dediščini soške fronte, «v: Finančni mehanizem EGP in Norveški finančni mehanizem za obdobje 2004-2009 v Sloveniji (Ljubljana: Služba Vlade Republike Slovenije za lokalno samoupravo in regionalno politiko, 2011), 74-75. Vodnik je izšel v štirih jezikovnih različicah: Tadej Koren, Muzeji na prostem prve svetovne vojne, Soška fronta, 1915-1917 (Kobarid: Ustanova Fundacija Poti miru v Posočju, 2009). Tadej Koren, The First World War Outdoor Museums. The Isonzo Front, 1915-1917, prev. Branka Klemenc (Kobarid: The Walks of Peace in the Soča Region Foundation, 2009). Tadej Koren, Freilichtmuseendesersten Weltkrieges. Isonzofront, 1915-1917, prev. Elke Arcet (Kobarid: Stiftung Wege des Friedens in Sočatal, 2009). Tadej Koren, Musei all'aperto della prima guerra mondiale, fronte isontino, 1915-1917, prev. Miha Obit (Kobarid: Ente Fondazione Le vie della pace nell'Alto Isonzo, 2009).

17 Društvo 13-13 na Bovškem (Čelo in Ravelnik), Turistično društvo Drežnica (Zaprikraj), Turistično društvo Kobarid (Kolovrat), Društvo Peski 1915-1917 iz Tolmina (Mrzli vrh) in Društvo Mengore (Mengore).

18 Glej: ZVKDS. Zavod za varstvo kulturne dediščine Slovenije, pridobljeno 28. 9. 2015, http:// www.zvkds.si/sl. 
Obiskovalci imajo tako priložnost na avtentičnih lokacijah opazovati način gradnje jarkov, utrdb in kavern ter podoživeti zgodbe vojakov med vojno. Dejstvo je, kot smo že zapisali, da je Zgornje Posočje gosto posejano z obeležji in ostalinami iz časa prve svetovne vojne, zato Fundacija skrbi za ohranjanje, vzdrževanje, čiščenje in po potrebi tudi obnovo te dediščine. ${ }^{19} \mathrm{Ob}$ Poti miru pa gre gotovo izpostaviti še enotno označevanje poti in objektov ob njej, saj je bilo že pri načrtovanju tega projekta vloženega veliko dela $\mathrm{v}$ celostno grafično podobo (informacijske table, smerokazi, markacije in logoti ${ }^{20}$ ), predvsem ob zavesti, da so vsa označevanja v naravi tujki; informacijske oznake so se morale čim bolje zlivati z okoljem, poleg tega pa ostati pregledne, preproste in razumljive vsem obiskovalcem. ${ }^{21} \mathrm{Za}$ lažje načrtovanje izletov in bolj izčrpne informacije o Poti miru je bil zasnovan tudi knjižni vodnik. ${ }^{22}$

Danes sodelavci na Fundaciji razvijajo projekt Pot miru kot zgodovinsko-turistični produkt, ${ }^{23}$ ki obiskovalcem ponuja čudovito naravo, a jih skuša v dolini zadržati za več dni tudi z resnejšimi vsebinami. Osnova Poti miru je vsekakor najprej ovrednotenje zgodovinske dediščine soške fronte, ki pa je obogatena s ponudbo ogleda

\section{Slika 4: Logotip Poti miru}

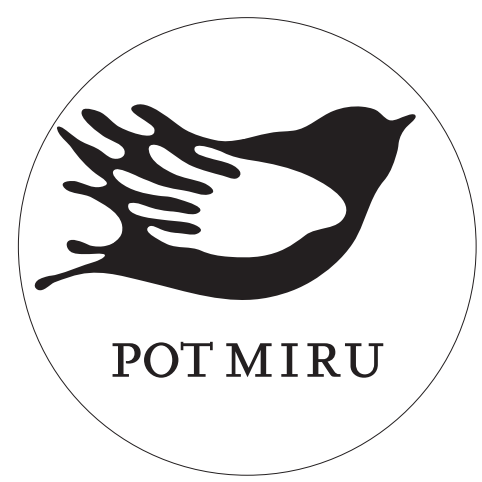

Vir: Ustanova "Fundacija Poti miru v Posočju«

19 Fundacija je do danes obnovila okrog trideset spominskih obeležij, ki so del Poti miru.

20 Logotip okrogle oblike umešča motiv črne ptice na belo podlago. Gre za novo simboliko, ki spominja na goloba z uveljavljeno simbolno vrednostjo, nadgrajuje pa jo perut te ptice, oblikovana kot človeška roka, spravno ponujena v znak miru. Skladno s to simboliko $\mathrm{k}$ logotipu sodi tudi napis Pot miru.

21 Koren, Testen, "Spomin, prostor in ostaline soške fronte«, 75.

22 Tadej Koren, Pot miru. Vodnik po soški fronti v Zgornjem Posočju (Kobarid: Ustanova Fundacija Poti miru v Posočju, 2007). Tadej Koren, Il Sentiero della pace, Guida lungo il fronte isontino nell'Alta valle dell'Isonzo, prev. Miha Obit (Kobarid: Fondazione Le vie della Pace nell'Alto Isonzo, 2007); Tadej Koren, Weg des Friedens, Führer der Isonzofront im oberen Sočatal, prev. Elke Arcet (Kobarid: Stiftung Wege des Friedens im Sočatal, 2007). Tadej Koren, The Walk of Peace, A Guide along the Isonzo Front in the Upper Soča Region, prev. Branka Klemenc (Kobarid: The Walks of Peace in the Soča Region Foundation, 2008).

23 Pri poimenovanju zgodovinsko-turistični produkt oziroma turistični produkt gre za uveljavljeno terminologijo v turizmu. Sodobna raba besede turistični produkt v tem smislu pomeni konkreten rezultat določenega projekta, ki vključuje ponudbo športnih aktivnosti, ogleda zgodovinske dediščine, gastronomskih pokušin, wellness storitev, poslovnega turizma itd. 
ostalih posebnosti pokrajine, kot so raznolika narava, zanimiva kultura, odkrivanje vsakdanjega življenja prebivalcev ter ponudba številnih športnih aktivnosti in gastronomije. Gre tudi za preprosto dejstvo, da je turistična sezona v Zgornjem Posočju kratka, skoncentrirana na poletno sezono, ki se podaljša $v$ jesen in pomlad $s$ pohodništvom in kolesarjenjem ter drugimi aktivnostmi v naravi, a tudi ponudbo bogatega programa na primer šolam in drugim izobraževalnim ustanovam (ekskurzije, vodeni programi po terenu). Vidik posredovanja dediščine prve svetovne vojne šoloobveznim otrokom in mladini je zelo pomemben, tako kot je pomembno širjenje zavesti, da sta mir in nenasilje vrednoti. Obenem si Fundacija prizadeva tudi za aktivnosti na področju znanstvenega in ljubiteljskega raziskovanja. Za ta namen sta vzpostavljena študijski center in zgodovinska knjižnica, kamor se neprestano steka raznovrstno gradivo o prvi svetovni vojni, za tovrstno delovanje pa so na razpolago urejeni prostori, kjer se prirejajo domače in gostujoče razstave, organizirajo različne delavnice, predavanja, konference ter simpoziji. ${ }^{24}$ Za širšo prepoznavnost deluje $\mathrm{v}$ njenih prostorih Informacijski center Pot miru, ${ }^{25}$ v sklopu katerega je bila leta 2012 postavljena interaktivna razstava o Poti miru, ki obiskovalcem z uporabo sodobne opreme in tehnologije na zanimiv način prikaže zgodovinsko dediščino soške fronte. Postavitev ponuja rekonstrukcijo strelskega jarka $\mathrm{z}$ avtentično vojaško opremo, interaktivne panorame iz muzejev na prostem ter zaslon na dotik s predstavitvijo Poti miru, dostop do podatkovne baze evidence padlih, možnost poslušanja glasbenega $\mathrm{CD}$ z vojaškimi pesmimi, predstavitev zasebnih muzejskih zbirk iz Posočja, promocijski material in tematske filme ter otroški kotiček. Uporabniki se tako lahko virtualno sprehajajo po Poti miru tudi v primeru slabega vremena, kar se v hribovi-

24 Naj na tem mestu omenimo mednarodno delavnico, ki se je odvijala tudi v prostorih Fundacije, in sicer oktobra 2014, ki se je dotaknila na Slovenskem dokaj neuveljavljenega (akademskega) področja, ki proučuje preplet turizma in izobraževanja, v svetu pa ga prepoznavajo pod izrazi dark tourism, black tourism (tudi grief tourism). Več glej: Anton Gosar, Miha Koderman in Mariana Rodela, ur., Temačni turizem. Prva svetovna vojna - stanje in razvojne možnosti tudistične ponudbe. / Dark tourism. Post-ww1-destinations of human tragedies and opportunities for tourism development. Zbornik povzetkov in ekskurzijski vodnik (Portorož, Koper: Univerza na Primorskem, Fakulteta za turistične študije - Turistica, 2014), pridobljeno 28. 9. 2015, http://www.turistica.si/temacni/wp-content/uploads/2014/10/ temacni-povzetki.pdf.

25 Vzdolž celotne trase Poti miru od Alp do Jadrana delujejo naslednji informacijski centri: v Sloveniji so to TIC Bovec (Bovec. Doline navdiha, pridobljeno 28. 9. 2015, http://www.bovec.si.). TIC Kobarid in TIC Tolmin (Dolina Soče. KOBARID, TOLMIN, pridobljeno 28. 9. 2015, http://www. dolina-soce.com.). TIC Kanal (Turistično informacijski center Kanal, pridobljeno 28. 9. 2015, http:// www.tic-kanal.si.). TIC Brda (Brda. Slovenija. Dežela opojnih trenutkov, pridobljeno 28. 9. 2015, http://www.brda.si.). TIC Nova Gorica (NOVA GORICA. Nova doživetja, pridobljeno 28. 9. 2015, http://www.novagorica-turizem.com.). TIC Miren, tic.miren@siol.net; TIC Temnica (POTI MIRU NA KRASU, pridobljeno 28. 9. 2015, http://www.potimirunakrasu.info.). TIC Štanjel (Štanjel, pridobljeno 28. 9. 2015, http://www.stanjel.eu.). V Italiji pa: Agenzia Turismo Friuli Venezia Giulia (FRIULI VENEZIA GIULIA, pridobljeno 28. 9. 2015, http://www.turismofvg.it.). Udine Infopoint, info. udine@turismo.fvg.it; Gorizia Infopoint, info.gorizia@turismo.fvg.it. IAT Fogliano Redipuglia (Pro Loco Fogliano - Redipuglia, pridobljeno 28. 9. 2015, http://www.prolocofoglianoredipuglia.it.). URP Monfalcone (Monfalcone. Pridobljeno 28. 9. 2015. http://www.comune.monfalcone.go.it.). Trieste Infopoint, info.trieste@turismo.fvg.it. Več glej: Koren, Pot miru od Alp do Jadrana, 207. 
tem svetu kaj hitro lahko dogodi. S tem se nadgrajuje ponudba in predstavlja (ne) snovna zgodovinska dediščina na inovativen način, hkrati pa se uspešno dopolnjujejo vsebine, ki jih v sosednji stavbi predstavlja zbirka Kobariškega muzeja. Informacijski center Pot miru, kjer obenem ponujajo svoje domače izdelke številni okoliški obrtniki in umetniški ustvarjalci, je odlično izhodišče za obiske ostalin v naravi, za kar je poskrbljeno z možnostjo organizirane vodniške službe. ${ }^{26}$

Fundacija je v zadnjih letih po vzor(c)u iz Zgornjega Posočja razširila projekt Pot miru ob nekdanji soški fronti proti jugu - na Goriško, Kras in vse do Tržaškega zaliva. ${ }^{27}$ Celotna trasa od Alp do Jadrana je, tako kot začetni "primer dobre prakse« v Zgornjem Posočju, enotno označena, razdeljena na petnajst odsekov in primerna za pohodnike ter kolesarje; poteka po pohodniških, kolesarskih in stranskih asfaltiranih cestah. Iz Kolovrata se pot tako nadaljuje mimo Korade, Goriških Brd, Sabotina do Nove Gorice, medtem ko del trase skrene čez Sočo že pri Plavah in vodi preko Prižnice, Vodic, Svete Gore in Škabrijela prav tako do Nove Gorice in nato dalje do Šempetra pri Gorici, Vrtojbe, Mirna in Cerja ter naprej na Komenski Kras. Tudi na tej trasi gre izpostaviti muzeje na prostem, in sicer Sabotin, Prižnica, Vodice, Škabrijel, Jama Pečinka. Pot miru pa se obenem nadaljuje na italijansko stran in vključuje tamkajšnje muzeje na prostem - Debela Griža (Monte San Michele), nov muzej na prostem Brestovec, Grmada (Monte Ermada), Dolina Bersaljerjev (Dolina dei Bersaglieri), Tematski park prve svetovne vojne (Parco Tematico della Grande Guerra) v Tržiču (Monfalcone) itd. - ter vodi mimo na primer monumentalne kostnice v Redipulji (Redipuglia), slikovitega Devinskega gradu vse do Trsta, do Jadranskega morja. Tako so pod skupni projekt vključene že obstoječe iniciative na Sabotinu in na Krasu, ${ }^{28}$ hkrati pa trasa sega na italijansko stran; onkraj zdaj že skoraj nevidne meje, in na območje, ki ga je nekoč ločevala frontna črta, pozneje pa so se tod postavljale in spreminjale državne meje, vnaša nove vsebine. Pot miru potemtakem ni samo pomemben regionalni, temveč tudi mednarodni projekt. ${ }^{29}$ Ob stoti obletnici bojev ob Soči je bila skupaj z vsemi slovenskimi in italijanskimi partnerji uradno odprta Pot miru od Alp do Jadrana, in sicer 21. marca 2015 - na Trgu Evrope (Piazza della Transalpina), ki povezuje Novo Gorico in Gorico. ${ }^{30}$

Razvijanje Poti miru kot zgodovinsko-turističnega produkta je vsekakor proces,

26 Da je Pot miru dober način predstavitve zgodovinske dediščine, dokazuje tudi za leto 2008 podeljeni laskavi naziv Evropska destinacija odličnosti. Podobno potrjuje leta 2012 dodeljena nagrada Zlato jabolko; Svetovno združenje turističnih novinarjev in piscev (FIJET) jo podeljuje vsako leto projektom, ki ohranjajo kulturno, naravno, etnološko in drugo dediščino.

27 Leta 2012 je Fundacija pripravila prvo zloženko s pregledno karto in opisi pomembnih objektov iz časa soške fronte od Alp do Jadrana. Glej: Pot miru od Alp do Jadrana, Soška fronta 1915-1917 (Kobarid: Ustanova Fundacija Poti miru v Posočju, 2012) (zloženka, zemljevid). Vse ključne informacije in promocijsko gradivo, vključno z zemljevidi, je dostopno na: POT MIRU.

28 Glej: POTI MIRU NA KRASU.

29 Koren, Testen, "Spomin, prostor in ostaline soške fronte«, 77-78.

30 Glej: "Foto: Slavnostno odprtje Poti miru od Alp do Jadrana, MMC RTV SLO. PRVI INTERAKTIVNI MULTIMEDIJSKI PORTAL, pridobljeno 28. 9. 2015, http://www.rtvslo.si/slovenija/ foto-slavnostno-odprtje-poti-miru-od-alp-do-jadrana/361068. 


\section{Slika 5: Italijanska kostnica, Kobarid, Slovenija}

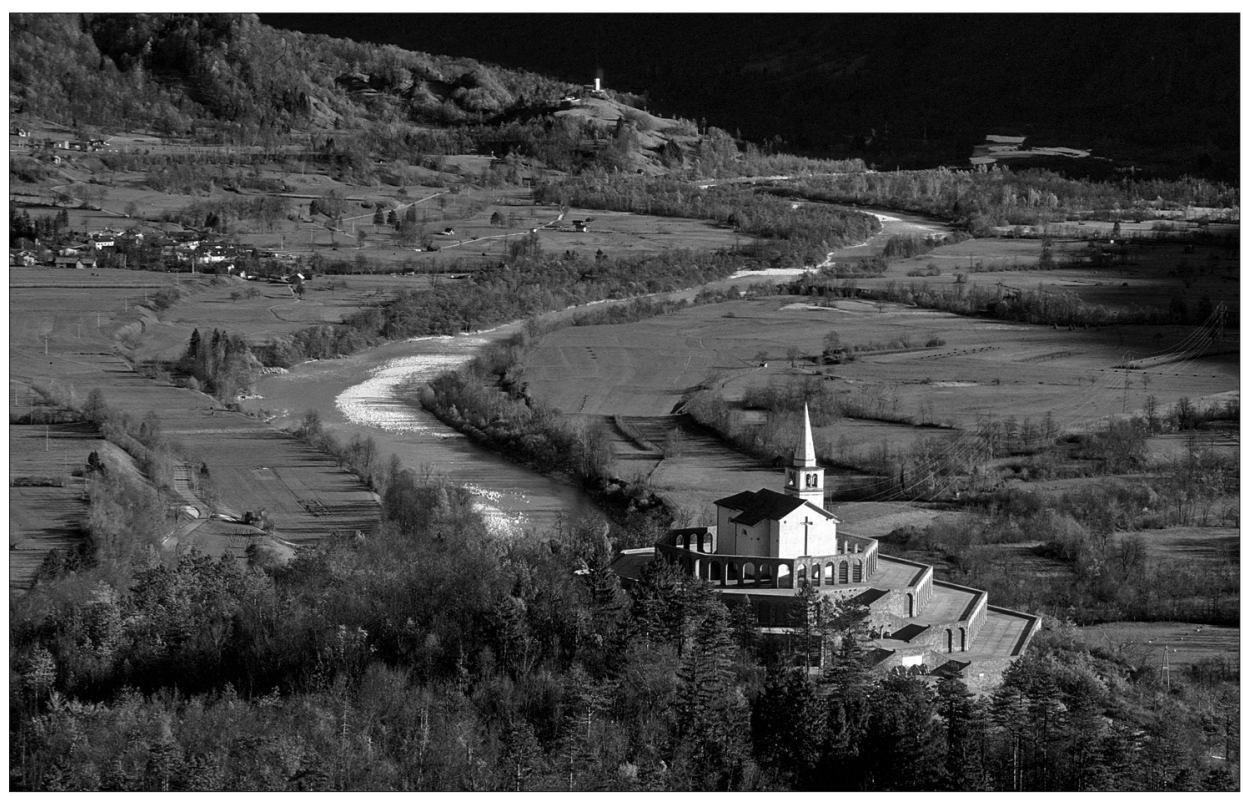

Vir: Ustanova "Fundacija Poti miru v Posočju»

na katerega je vplivalo in še vedno vpliva več dejavnikov. Med slednjimi gre še enkrat opozoriti na pomen ohranjanja zgodovinske dediščine soške fronte v naravi. To na eni strani prispeva $\mathrm{k}$ močnejši kolektivni zavesti prebivalcev v dolini Soče, na drugi strani pa h krepitvi in soustvarjanju zgodovinskega spomina. Slednje se odslikava na več nivojih: najprej v lokalni skupnosti, ki se pomena dediščine soške fronte vse bolj zaveda in ima od povečanega obiska muzejev, zbirk, vodenih izletov itd. tudi ekonomsko korist; nato na ravni države, kjer se v javnosti krepi zavest o pomembnih zgodovinskih dogodkih, ki so se odvijali ob reki Soči; slednjič pa je tu še mednarodni okvir, v katerem soška fronta postaja vse bolj prepoznavna kot skupna dediščina, Posočje pa kot prostor vseevropskega spominjanja. ${ }^{31}$

Danes je prav Pot miru ena najpomembnejših pobud, ki pomaga ustvarjati skupni prostor, skupno regijo med Slovenijo in Italijo, jutri pa morda tudi Avstrijo na severu. A to je seveda le en vidik skupnega prostora, ki se lahko razvija na podlagi ideje o miru in povezovanju ter hkrati nudi vpogled v skupno spominsko dediščino, ki so jo skrojila dogajanja na političnem parketu 20. stoletja. Vsekakor je za uspešno in v prihodnost zazrto izvajanje projekta Pot miru pomembno, da ves čas živi in se razvija, za to pa morajo delovati vsi v besedilu našteti vidiki - od študijskega in raziskovalnega ter seveda didaktičnega do turističnega, in sicer na vseh ravneh, tj. na lokalnem, državnem in mednarodnem nivoju.

Pot miru ima glede na zapisano odličen potencial, da kot »didaktični pripomo-

31 Koren, Testen, »Spomin, prostor in ostaline soške fronte«, 78. 
ček“ ponudi svoj delež k razumevanju dogodkov, ki so pred sto leti pretresli prebivalce Posočja in vse, ki so bili v vojno svetovnih razsežnosti vpleteni. Pomaga lahko h konkretni umestitvi zgodovinskih dejstev na geografsko točno določene (slikovite) lokacije, torej deluje kot učilnica na prostem, hkrati pa odpira vprašanja spomina, vrednotenja miru in sožitja in s tem kakovostno prispeva $\mathrm{k}$ učnemu procesu. Ne nazadnje je prav slednje - skrb za nepremično dediščino soške fronte in njeno posredovanje čim širšemu krogu - glavna naloga Ustanove »Fundacija Poti miru v Posočju«, ki je tudi poglavitna skrbnica Poti miru od Alp do Jadrana.

"Pot miru nagovarja z jezikom, ki je pred stotimi leti izginil iz človeškega obzorja sporazumevanja, danes pa samoumevno prehaja v prostor in vijuga preko nekdanje meje, ki je predolgo ločevala, a je s slovenskim vstopom v območje Schengena izgubila še zadnji fizični argument ločevanja. Pot miru pa je veliko več, ker vstopa v območje spomina, ki ima nenavadno moč pozabljenja in opominjanja, ima kreativno moč ustvarjanja skupnega prostora spomina, ki spoštuje, ker pozna in brez predsodkov pripoveduje zgodovinsko zgodbo prostora in ljudi ob Soči. 32

\section{Viri in literatura}

Internetni viri:

- Associazione Storica Cimeetrincee. Pridobljeno 28. 9. 2015. http://www.cimeetrincee.it.

- CarniaMusei. Pridobljeno 28. 9. 2015. http://www.carniamusei.org.

- Castello di Duino. Pridobljeno 28. 9. 2015. http://www.castellodiduino.it.

- Bovec. Doline navdiha. Pridobljeno 28. 9. 2015. http://www.bovec.si.

- Brda. Slovenija. Dežela opojnih trenutkov. Pridobljeno 28. 9. 2015. http://www.brda.si.

- Dolina Soče. KOBARID, TOLMIN. Pridobljeno 28. 9. 2015. http://www.dolina-soce.com.

- Dolomitenfreunde. Pridobljeno 28. 9. 2015. http://www.dolomitenfreunde.at.

- firstworldwar.com. a multimedia history of world war one. "Battles - The Battle of the Somme, 1916.«Pridobljeno 28. 9. 2015. http://www.firstworldwar.com/battles/somme.htm.

- firstworldwar.com. a multimedia history of world war one. »Battles - The Battle of Verdun, 1916." Pridobljeno 28. 9. 2015. http://www.firstworldwar.com/battles/verdun.htm.

- FRIULI VENEZIA GIULIA. Pridobljeno 28. 9. 2015. http://www.turismofvg.it.

- Goriški muzej. Pridobljeno 28. 9. 2015 (stran trenutno v popravilu). http://www.goriskimuzej.si.

- Gosar, Anton in Miha Koderman in Mariana Rodela, ur., Temačni turizem. Prva svetovna vojnastanje in razvojne možnosti tudistične ponudbe. / Dark tourism. Post-ww1-destinations of human tragedies and opportunities for tourism development. Zbornik povzetkov in ekskurzijski vodnik. Portorož, Koper: Univerza na Primorskem, Fakulteta za turistične študije - Turistica, 2014. Pridobljeno 28. 9. 2015. http://www.turistica.si/temacni/wp-content/uploads/2014/10/temacni-povzetki.pdf.

- Grandeguerra.Dolomiti.Org. Pridobljeno 28. 9. 2015. http://www.grandeguerra.dolomiti.org.

- H. MUSEO DELla GUERRA PER LA PACE DIEGO DE HENRIQUEZ. Pridobljeno 28. 9. 2015. http://www.museodiegodehenriquez.it.

- I LUOGHI DELLA GRANDE GUERRA NEL FRIULI COLLINARE. RAGOGNA, FORGARIA NEL FRIULI E SAN DANIELE DEL FRIULI. Pridobljeno 28. 9. 2015. http://www.grandeguerra-ragogna.it.

- IN FLANDERS FIELDS MUSEUM. Pridobljeno 28. 9. 2015. http://www.inflandersfields.be/ en/discover.

- KOBARIŠKI MUZEJ. Pridobljeno 28. 9. 2015. http://www.kobariski-muzej.si.

32 Svoljšak, „Vodniku na pot«, 11. 
- MÉMORIAL DE VERDUN. Réouverture en février 2016. Pridobljeno 28. 9. 2015. http://www. memorial-de-verdun.fr.

- MMC RTV SLO. PRVI INTERAKTIVNI MULTIMEDIJSKI PORTAL. "Foto: Slavnostno odprtje Poti miru od Alp do Jadrana.« Pridobljeno 28. 9. 2015. http://www.rtvslo.si/slovenija/foto-slavnostno-odprtje-poti-miru-od-alp-do-jadrana/361068.

- Monfalcone. Pridobljeno 28. 9. 2015. http://www.comune.monfalcone.go.it.

- Musée de la Première Guerre mondiale / 1914-1918. HISTORIAL DE LA GRANDE GUERRE. Péronne - Thiepval / Somme. Pridobljeno 28. 9. 2015. http://www.historial.org.

- Musée de la Première Guerre mondiale / 1914-1918. HISTORIAL DE LA GRANDE GUERRE. „CIRCUIT DU SOUVENIR.« Pridobljeno 28. 9. 2015. http://www.historial.org/Champs-de-bataille-de-la-Somme/Circuit-du-souvenir.

- MUSEO STORICO ITALIANO DELLA GUERRA. Pridobljeno 28. 9. 2015. http://www.museodellaguerra.it.

- NOVA GORICA. Nova doživetja. Pridobljeno 28. 9. 2015. http://www.novagorica-turizem.com.

- POT MIRU. Pridobljeno 28. 9. 2015. http://www.potmiru.si.

- POT MIRU. »Evidenca padlih.« Pridobljeno 28. 9. 2015. http://www.potmiru.si/slo/evidenca-padlih.

- POTI MIRU NA KRASU. Pridobljeno 28. 9. 2015. http://www.potimirunakrasu.info.Pro Loco Fogliano - Redipuglia. Pridobljeno 28. 9. 2015. http://www.prolocofoglianoredipuglia.it.

- STELVIO-UMBRAIL 14/18. Mit uns in die Geschichte wandern. Pridobljeno 28. 9. 2015. http:// www.stelvio-umbrail.ch

- Štanjel. Pridobljeno 28. 9. 2015. http://www.stanjel.eu.

- THE GREAT WAR 1914-1918. "Thiepval Memorial to the Missing, Somme Battlefields, France.« Pridobljeno 28. 9. 2015. http://www.greatwar.co.uk/somme/memorial-thiepval.htm.

- Toerisme Ieper. Pridobljeno 28. 9. 2015. http://www.toerisme-ieper.be.

- Tolminski muzej. Pridobljeno 28. 9. 2015. http://www.tol-muzej.si.

- Turistično informacijski center Kanal. Pridobljeno 28. 9. 2015. http://www.tic-kanal.si.

- ZVKDS. Zavod za varstvo kulturne dediščine Slovenije. Pridobljeno 28. 9. 2015. http://www. zvkds.si/sl.

- Zborzbirk. "Kulturna dediščina v zbirkah med Alpami in Krasom. / L'eredità culturale nelle collezioni fra Alpi e Carso.« Pridobljeno 28. 9. 2015. http://zborzbirk.zrc-sazu.si.

\section{Literatura:}

- Brait, Andrea. "Der Isonzoraum - Ein transnationaler Gedächtnisort für Österreicher, Italiener und Slowenen."V: Waffentreue. Die 12. Isonzoschlacht 1917, Begleitband zur Ausstellung des Österreichischen Staatsarchiv, 23. Oktober 2007-1. Februar 2008, ur. Manfried Rauchensteiner, 115-30. Wien: Österreichischen Staatsarchiv, 2007.

- Galić, Lovro in Branko Marušič. Tolminsko mostǐ̌če I. Tolmin: Tolminski muzej, 2005.

- Galić, Lovro in Darja Pirih. Od Krna do Rombona. Kobarid: Ustanova Fundacija Poti miru v Posočju, Tolminski muzej, 2007.

- Halbwachs, Maurice. Kolektivni spomin. Ljubljana: Studia humanitatis, 2001.

- Koren, Tadej. „Das Erbe der Isonzofront nach 100 Jahren - Weg des Friedens." V: Krieg und Tourismus im Spannungsfeld des Ersten Weltkrieges / Guerra e turismo nell'area di tensione della prima guerra mondiale, ur. Patrick Gasser, Andrea Leonardi, Gunda Barth-Scalmani, 445-66. Tourism \& Museum: Studienreihe des Touriseum / Collana del Touriseum / Touriseum Study Series , Band 5, Vol. 5, Innsbruck, Wien, Bozen: Studien Verlag, 2014.

- Koren, Tadej. Freilichtmuseendesersten Weltkrieges. Isonzofront, 1915-1917. Prev. Elke Arcet. Kobarid: Stiftung Wege des Friedens in Sočatal, 2009.

- Koren, Tadej. Il Sentiero della pace. Guida lungo il fronte isontino nell'Alta valle dell'Isonzo. Prev. Miha Obit. Kobarid: Fondazione Le vie della Pace nell'Alto Isonzo, 2007.

- Koren, Tadej. Il Sentiero della pace dalle Alpi all'Adriatico. Guida lungo il fronte isontino. Prev. Michele Obit. Kobarid: Ustanova Fundacija Poti miru v Posočju, 2015. 
- Koren, Tadej. Musei all'aperto della prima guerra mondiale, fronte isontino, 1915-1917. Prev. Miha Obit. Kobarid: Ente Fondazione Le vie della pace nell'Alto Isonzo, 2009.

- Koren, Tadej. Muzeji na prostem prve svetovne vojne, Soška fronta, 1915-1917. Kobarid: Ustanova Fundacija Poti miru v Posočju, 2009.

- Koren, Tadej. "Pot po dediščini soške fronte.« V: Finančni mehanizem EGP in Norveški finančni mehanizem za obdobje 2004-2009 v Sloveniji. 74-75. Ljubljana: Služba Vlade Republike Slovenije za lokalno samoupravo in regionalno politiko, 2011.

- Koren, Tadej. Pot miru. Vodnik po soški fronti v Zgornjem Posočju. Kobarid: Ustanova Fundacija Poti miru v Posočju, 2007.

- Koren, Tadej. Pot miru od Alp do Jadrana. Vodnik po soški fronti. Kobarid : Ustanova Fundacija Poti miru v Posočju, 2015.

- Koren, Tadej. The First World War Outdoor Museums. The Isonzo Front, 1915-1917. Prev. Branka Klemenc. Kobarid: The Walks of Peace in the Soča Region Foundation, 2009.

- Koren, Tadej. The Walk of Peace. A Guide along the Isonzo Front in the Upper Soća Region. Prev. Branka Klemenc. Kobarid: The Walks of Peace in the Soča Region Foundation, 2008.

- Koren, Tadej. The Walk of Peace from the Alps to the Adriatic. A guide along the Isonzo Front. Prev. Branka Klemenc. Kobarid: Ustanova Fundacija Poti miru v Posočju, 2015.

- Koren, Tadej. Weg des Friedens. Führer der Isonzofront im oberen Sočatal. Prev. Elke Arcet. Kobarid: Stiftung Wege des Friedens im Sočatal, 2007.

- Koren, Tadej. "Zgodovinski spomin na soško fronto - Pot miru od Rombona do Mengor.« Magistrsko delo, Filozofska fakulteta Univerze v Ljubljani, 2012.

- Koren, Tadej in Petra Testen. "Spomin, prostor in ostaline soške fronte: primer Poti miru. "V: Velika vojna in mali ljudje, ur. Igor Grdina, 67-78. Šentjur: Knjižnica; Ljubljana: Inštitut za civilizacijo in kulturo - ICK, 2014.

- Koren, Tadej in Petra Testen. „Vospominanie o Pervoj mirovoj vojne. Rol' prostranstva i nasledija Sočanskogo fronta dlja zitelej Posočja." V: Slovenica. 3, Pervaja mirovaja vojna v politike i kul'ture Russkih $i$ Slovencev: $k$ stoletiju načala pervoj mirovoj vojny, ur. Konstantin V. Nikiforov, 252-75. Moskva: Institut slavjanovedenija Rossijskoj akademii nauk, 2014.

- Marušič, Branko. Pregled politične zgodovine Slovencev na Goriškem:1848-1899. Nova Gorica: Goriški muzej, 2005.

- Pot miru od Alp do Jadrana, Soška fronta 1915-1917, Kobarid: Ustanova Fundacija Poti miru v Posočju, 2012 (zloženka, zemljevid).

- Svoljšak, Petra, Darja Pirih, Damjana Fortunat Černilogar in Lovro Galić. Tolminsko mostišče II. Tolmin: Tolminski muzej, 2005.

- Winter, Jay in Emmanuel Sivan. "Setting the framework."V: War and Remembrance in the Twentieth Century, ur. Jay Winter in Emmanuel Sivan, 6-39. Cambridge, New York, Melbourne, Madrid, Cape Town, Singapore, São Paulo: Cambridge University Press, 2005.

Petra Testen, Tadej Koren

OPENAIR CLASSROOM: THE WALK OF PEACE EXAMPLE

\section{S UMMARY}

The Walk of Peace from the Alps to the Adriatic is a project created under the auspices of the "Walk of Peace in the Soča Region Foundation «, located in Kobarid. It is a trail following the remnants of the Isonzo Front, which is why it can provide very concrete foundations for the historical facts that the pupils learn about, at the theoretical level, during the pedagogical process in schools. In this manner the trail functions as a (picturesque) openair classroom, while focusing on the important questions of remembrance, value of peace and harmony, and thus making an important contribution to the pedagogical process. After all, the main task of the Kobarid Foundation - the main caretaker of the whole Walk of Peace from the Alps to the Adriatic trail - is to protect the onsite heritage of the Isonzo Front and present it, also conceptually, to as many people as possible. 
The article attempts to provide answers to the following questions: What is the Walk of Peace from the Alps to the Adriatic and why is this project suitable as an openair classroom? What is it that makes it special and interesting? Which elements of this project have didactic potential? What are the origins and messages of this idea? Why call it the Walk of Peace? What is an area of remembrance? The answers to these questions create a story containing the narratives of the locations by the river Soča, lives of the inhabitants of this basin of the emeraldgreen river, and the role and value of memories and remembrance. The story represents the ties between the past, present, and future. This is the common „space“ for all of us: with our understanding of the past we should communicate the values and knowledge to the future generations, thus contributing to a brighter and betterunderstood future. This is the added value of the Walk of Peace from the Alps to the Adriatic and its invaluable didactic potential. The article describes how the Walk of Peace project has been realised over the years and how it provides numerous possibilities to its visitors: from sightseeing to study, research and didactic activities. 